\title{
a crítica à teoria consagrada de caio prado jr. atinge octavio brandão? aparando as arestas para uma (re)interpretação das origens do marxismo brasileiro*
} does the criticism of caio prado jr.'s theory reach octavio brandão? smoothing out rough edges for a (re)interpretation of the origins of brazilian marxism

\author{
Filipe Leite Pinheiro $\star \star$ \\ Departamento de Ciências Econômicas, Universidade Federal Rural do Rio de Janeiro, Seropédica, \\ Rio de Janeiro, Brasil
}

RESUMO

Respondendo ao questionamento formulado no título, nesse artigo pretendo relativizar o alcance da crítica à teoria consagrada, elaborada por Caio Prado Jr. Tal relativização contribui para uma reapreciação do legado teórico de Octavio Brandão e permite sua caracterização como pioneiro do marxismo brasileiro. Para isso, apresento as relações entre a Internacional Comunista (IC) e o Partido Comunista Brasileiro (PCB), a crítica à teoria consagrada de Caio Prado Jr., bem como as principais formulações de Brandão. Argumento que quando o alvo dessa crítica é Brandão, seu alcance é apenas parcial: embora seja correta em um nível de abstração mais elevado, é improcedente a crítica que atribui a Brandão uma incompreensão das peculiaridades subjacentes à formação social brasileira.

Palavras-chave: Interpretações do Brasil. Pensamento social brasileiro. Revolução brasileira. Octavio Brandão. Caio Prado Jr.

\section{Abstract}

Answering the question posed in the title of this article, I intend to make relative the scope of the criticism of the consecrated theory, elaborated by Caio Prado Jr., and thus contribute to a review of the theoretical legacy of Octavio Brandão that allows him to be characterized as a pioneer of Brazilian Marxism. To this end, I make a presentation of the relations between the Communist International and the Brazilian Communist Party (PCB), and the critique of the consecrated theory of Caio Prado Jr., as well as the trajectory and main formulations of Brandão, arguing that the scope of this criticism is only partial. I conclude that, although it is correct at a higher level of abstraction, the criticism that Brandão did not understand the peculiarity underlying Brazilian social formation is unfounded.

Keywords: Interpretations of Brazil. Brazilian social thought. Brazilian revolution. Octavio Brandão. Caio Prado Jr.

* Submissão: 25/08/2018; aprovação: 29/11/2019.

$\star \star$ Professor substituto do Departamento de Ciências Econômicas (DeCE) da Universidade Federal Rural do Rio de Janeiro (UFRRJ) e doutorando pelo Programa de Pós-Graduação em Economia (PPGE) da Universidade Federal Fluminense (UFF). ORCID: < https://orcid.org/0000-0002-1861-9827>. Agradeço aos pareceristas pelos comentários e especialmente a Rodrigo Castelo pelas sugestões. Os erros e omissões são de total responsabilidade do autor. 


\section{Introdução}

Talvez o mais popular dentre os intelectuais que elaboraram imagens marxistas do Brasil, Caio Prado Jr. (1907-1990) é referência incontornável no debate sobre a formação social e a revolução brasileira ${ }^{1}$. Dois elementos de seu pensamento contribuem para tal notoriedade. Em primeiro lugar, contribui para isso sua formulação sobre o sentido da colonização, isto é, a tese de acordo com a qual o desenvolvimento histórico brasileiro seria capitalista desde o princípio da colonização. Em segundo lugar, tomando essa tese como fundamento, em sua obra A revolução brasileira ([1966] 2014), o autor elabora uma crítica à esquer$\mathrm{da}$ às teses do Partido Comunista Brasileiro (PCB). Nos termos dessa crítica, a raiz dos equívocos do $\mathrm{PCB}$ encontra-se na caracterização do desenvolvimento histórico brasileiro como um processo histórico dotado de uma etapa feudal, resultado da importação dos preceitos da III Internacional Comunista (IC). Esta seria a teoria consagrada por Moscou, e portanto, alheia às especificidades da realidade nacional.

Já Octavio Brandão² (1896-1980), por sua vez, embora apresente uma formulação extremamente influente no PCB ao longo dos anos 1920, é um intérprete renegado do marxismo brasileiro. Confluência de um estilo obscuro, formulações teoricamente incipientes e posicionamentos impopulares, sua obra Agrarismo e industrialismo: ensaio marxista leninista sobre a revolta de São Paulo e a guerra de classes no Brasil - 1924 ([1926] 2006), não foi devidamente reconhecida como obra fundadora de uma leitura marxista sobre a formação social e a revolução brasileira. Embora o livro defenda a existência de feudalismo no Brasil e se inspire, em alguma medida, no arcabouço teórico da IC, há na análise uma preocupação constante com a definição da peculiaridade da formação social brasileira. Isso é patente na originalidade do uso da dico-

1 No ranking dos interpretes do Brasil que despertam maior interesse por parte dos pesquisadores, presente em Rodrigues (2019, p. 503), Caio Prado Jr. aprece em segundo lugar, com 20,9\% das respostas, atrás apenas de Florestan Fernandes, com $22,9 \%$ das respostas.

2 Como nota Bianchi (2012, p. 133), a grafia correta do nome é "Octavio", embora o nome do autor apareça acentuado em alguns comentadores, como, por exemplo, Pinheiro (1991). Em Combates e batalhas (1978), o nome não aparece acentuado em nenhum momento. 
tomia agrarismo-industrialismo para analisar o desenvolvimento histórico brasileiro, como na teoria da revolução democrática pequeno-burguesa, para apontar traços idiossincráticos da revolução no Brasil.

Muito embora Brandão seja identificado com a teoria consagrada por Moscou, como é nítido no título da sua obra, e se aproxime dela em alguns aspectos, há um exagero no peso da influência da IC nas formulações primevas do teórico do PCB. Esse exagero reside precisamente na afirmação de acordo com a qual Brandão não teria, em suas análises, captado a especificidade histórica da formação social brasileira. Tal ponto de vista encontra respaldo na leitura de Caio Prado Jr. da história da esquerda dos anos 1920 aos anos 1960 e, sobretudo, em sua crítica à teoria consagrada. À medida que Brandão realiza uma análise da peculiaridade da formação social brasileira, é possível considerar que a crítica à teoria consagrada de Caio Prado Jr. se adéqua, apenas parcialmente, a Agrarismo e industrialismo.

Começo tratando do processo de aproximação do PCB com a IC em dois momentos: o primeiro, da sua fundação em 1922; e o segundo após o VI Congresso da IC, em 1928. No interregno que vai de sua fundação aoVI Congresso, certa negligência da IC forneceu espaço para as formulações originais, que captaram a especificidade da formação social brasileira. Após oVI Congresso tais condições se erodem gradualmente, com a consolidação do stalinismo. Em seguida, apresento a crítica de Caio Prado Jr. à teoria consagrada e a tese do sentido capitalista da colonização, esta última fundamento da primeira. Por último, desenvolvo aspectos que permitem afirmar a imagem marxista do Brasil de Octavio Brandão como reflexão absolutamente original sobre a realidade brasileira. Em que pese à aproximação do autor ao esquematismo das formulações da IC, sobretudo em níveis de abstração mais elevados, existem momentos, como é o caso de sua teoria da revolução democrática pequeno-burguesa, em que saltam aos olhos o enraizamento da análise na realidade nacional.

\section{A teoria consagrada e as origens do comunismo brasileiro}

Conforme relato do militante Afonso Schmidt, em Bom tempo (1958), 
a fundação do PCB seria resultado da visita de um enviado da III Internacional Comunista (IC) à América Latina. Esse enviado, de nome Ramison, foi incumbido da tarefa de estabelecer partidos comunistas por todo o continente. Devido ao título da crônica cujo relato é feito, Ramison entraria para a história como "O cometa de Manchester". Schmidt foi surpreendido na redação do jornal $A$ vanguarda, em São Paulo, no horário do almoço, por um homem de estatura mediana com uma pasta de couro debaixo do braço e um longo chapéu de fibra sobre a cabeça. O homem lhe perguntou, em castelhano: “O dono está?”. De pronto, Schmidt informou-lhe que o jornal era uma cooperativa libertária, portanto, não havia dono. Ao ser indagado sobre o mais velho e experiente, indicou-lhe Edgard Leuenroth, que havia saído para almoçar. Quando regressou do almoço e deparou-se com o cartão do suposto representante de uma fábrica de tecidos de Manchester, Leuenroth hesitou por um instante, mas foi se encontrar com o homem naquela noite (Schmidt, 1958, p. 353-354; Dulles, 1977, p. 138; Bandeira, 2017, p. 387).

Na manhã seguinte, ao entrar na redação de $A$ vanguarda, Leuenroth revelou a Schmidt e a outros companheiros o verdadeiro propósito de Ramison; o homem era um enviado da Agência de Propaganda para a América do Sul da III IC em viagem ao Brasil. Surpreso com a inexistência de um partido comunista no país, a despeito da relativa mobilização do movimento operário, Ramison inquiriu Leuenroth sobre a possiblidade de criação de um partido comunista. Respondendo negativamente, Leuenroth se justificou: "Porque não sou bolchevista". Entretanto, Leuenroth indicou Astrojildo Pereira, à época morador do Rio de Janeiro, como potencial colaborador para o projeto de Ramison. Passados três dias, Astrojildo chega a São Paulo em um vagão de segunda classe e é apresentado ao "cometa", com quem iniciou relações políticas e pessoais que culminariam na fundação do PCB (Bandeira, 2017, p. 378; Schmidt, 1958, p. 353-354).

Esse momento pode ser tomado como marco inicial das tortuosas relações da IC com o PCB. Entretanto, episódios de natureza anedótica, como esse, são insuficientes para explicar um processo complexo como a formação de um partido político. $\mathrm{O}$ processo de formação do $\mathrm{PCB}$ deve ter seu marco analítico referenciado na formação da classe trabalhadora brasileira e, sobretudo, em sua tomada de consciência dos problemas 
políticos do país. Tal processo de elaboração teórica dos problemas da prática política, serve como acicate para a formulação de interpretações marxistas da realidade brasileira, isto é, análises que se debrucem sobre a peculiaridade da formação social brasileira para transformá-la. Sendo a principal organização da classe trabalhadora brasileira, o PCB exerce papel privilegiado no período que se estende de sua fundação até, ao menos, meados dos anos 1970.

Nesse sentido, as origens do $\mathrm{PCB}$ remontam às greves que transcorrem entre 1917 e $1921^{3}$, contexto no qual o partido se forma a partir do movimento sindical anarquista atuante ao longo da Primeira República. Esse processo tem dois momentos marcantes. O primeiro é o ensaio de fundação do PCB, em 1919, quando os militantes anarquistas, influenciados pela Revolução Russa, flertaram pela primeira vez com os métodos organizativos bolcheviques. A organização seria dissolvida após a chegada das notícias sobre as divisões entre anarquistas e bolchevistas na Rússia e na Ucrânia. Outro ponto digno de destaque é o fato de no período se apresentarem as primeiras tentativas de equacionar uma análise da revolução brasileira: o texto de Helio Negro e Edgard Leuenroth, $O$ que é o maximismo ou bolchevismo. Programa comunista ([1919] 2017), e Princípios e fins do programa anarquista-comunista (1919), de José Oiticica. A principal limitação desses textos se encontra na ausência de uma análise da formação econômica e social brasileira capaz de servir como fundamento à análise da revolução brasileira.

A cisão entre bolchevistas e "anarquistas puros" no movimento sindical, em 1922, é o marco da fundação do PCB e o resultado de um processo de acúmulo de tensões em torno da política de reorganização do movimento operário que transcorria desde a dissolução do primeiro PC. Tais tensões decorriam de um balanço negativo da greve de 1917, dada a não efetivação dos aumentos salariais e a perseguição das lideranças sindicais. Sem ter qualquer tradição marxista ou socialista previamente

3 Ocorre entre 1917 e 1921 o segundo ciclo de greves da Primeira República. Segundo Mattos (2009, p. 53), ocorreram no Rio de Janeiro: 1917 - 13 greves; 1918 - 29; 1919 - 26;1920 - 26;1921 - 4. Nota-se que o desaquecimento das greves coincide com as análises do IV Congresso da IC sobre a perda de força da revolução mundial; ou seja, o PCB já emerge em um momento de afluxo do movimento operário e de virada de IC para a linha de frente única. 
estabelecida ${ }^{4}$ e muito menos uma cultura política burguesa pujante com as quais dialogar, e sob forte influência da Revolução Russa, os militantes anarquistas emularam os métodos organizativos bolcheviques como uma forma de defesa contra tais perseguições (Antunes, 1995, p. 27).Em uma perspectiva mais ampla, o processo de complexificação da estrutura produtiva colocou para a classe trabalhadora em geral, e para os comunistas em especial, a necessidade da organização política e eleitoral dessa classe (Mazzeo, 1999, p. 20). Ao mesmo tempo, pela origem sindical da maioria dos seus quadros, viam nessas organizações o local ideal para aglutinar trabalhadores e formar uma vanguarda revolucionária (Mattos, 2009, p. 50).

Os primeiros integrantes das fileiras do PCB seriam formados em um caldo de cultura no qual Karl Marx era apenas mais uma esparsa referência, associada ecleticamente a uma miríade de outros pensadores anarquistas, como Bakunin e Kropotkin, ou positivistas, como Comte e Spencer (Aricó, 1987, p. 422; Batalha, 2014, p. 12). O positivismo era influente nesses meios como ferramenta de análise do cenário histórico, econômico e político nacional ${ }^{5}$, desempenhando o papel de uma ideologia progressista em uma configuração social de reacionarismo e predomínio do pensamento conservador (Zaidan, 1985, p. 19-20).

Do que foi exposto é possível depreender duas conclusões. A primeira é que as raízes bolchevizadas do PCB resultam mais das condições políticas e organizativas da classe trabalhadora brasileira do que da interferência política direta da IC no partido; a adoção do modelo de organização bolchevique é uma das respostas possíveis à época para as novas necessidades organizativas então surgidas. Em segundo lugar, dadas as trajetórias políticas dos primeiros militantes do PCB, existiam desde o princípio afinidades prévias entre a matriz intelectual subjacente às formulações desses quadros e aquela proposta pela Internacional

4 Existiram tentativas de organizar um movimento sindical socialista no Brasil ainda no final do século XIX e nas primeiras décadas dos anos 1920. Mattos (2009, p. 46) atribui a má fortuna dos socialistas à sua ênfase na luta política em detrimento da luta sindical.

5 Os exemplos da relação entre marxismo e positivismo vão muito além das formulações de Brandão. Por exemplo, Leônidas de Resende, autor de A formação do capital e seu desenvolvimento ([1932] 2011), e Edgardo de Castro Rebello, autor de Mauá e outros estudos ([1931] 1975), ambos professores da Faculdade Nacional de Direito, eram adeptos de uma interpretação positivista do marxismo. 
Comunista - ambas enormemente influenciadas pelo materialismo mecânico, padecem do determinismo e do logicismo positivista. Outras afinidades também podem ser apontadas na assimilação da tese sobre a existência de feudalismo no Brasil, considerando a existência prévia no pensamento social brasileiro e na historiografia de uma corrente de interpretação postulante da existência de uma etapa feudal para o desenvolvimento do país - por exemplo, em autores como: Capistrano de Abreu, Oliveira Vianna, Nestor Duarte e Gilberto Freire (Mazzeo, 2003, p. 154-155).

A participação polêmica do militante libertário Bernardo Canellas no IV Congresso da IC serve como alerta para dirimir exageros ao tratar de tais afinidades. A defesa da maçonaria por parte de Canellas e suas discordâncias com a direção da IC - leia-se: Lênin e Trotski - sobre a falta de democracia interna na nova estrutura da organização então em votação, que determinava que as reuniões das seções locais passariam a ocorrer depois, e não antes, dos congressos da IC,criaram as condições de um impasse responsável pelo atraso em dois anos na admissão do PCB como partido membro da Internacional (Zaidan, 1985, p. 58-60). Em dezembro de 1922, o Comitê Executivo da Internacional, com parecer de Boris Souvarine (1895-1984), publicou um relatório indicando seu parecer contrário ao reconhecimento do PCB como membro imediato, admitindo-o apenas como simpatizante. Sua justificativa era o fato de o PCB carregar em seu seio resquícios de ideologias burguesas como a maçonaria (Dulles, 1977, p. 167;Bandeira, 2017, p. 391).

Rodolfo Ghioldi, militante do Partido Comunista Argentino (PCA) - membro da IC desde 1921 -, seria o enviado da Comissão Executiva da Internacional, em 1924, para verificar as providências que tinham sido tomadas em relação a Canellas. Resistindo diante da imposição de fazer uma autocrítica, Canellas divulga o relatório entregue ao PCB como resultado de sua viagem, episódio que culmina em sua expulsão do partido. O relatório de Ghioldi para a IC considerou válidas as medidas tomadas contra Canellas e conforme os princípios da Internacional, a estrutura, a tática e a orientação política do PCB. O partido aceitava, inclusive, a adoção da tática parlamentar e eleitoral proposta pela IC. Isso permitiu a melhora das relações entre a IC e o PCB e pavimentou o caminho para a ida de Astrojildo Pereira e Rodolfo Coutinho ao V Congresso da IC como delegados do Brasil, selando a entrada do PCB 
como membro formal da organização (Dulles, 1977, p. 168; Pinheiro, 1991, p. 151).

A partir doV Congresso da IC (1924) a organização estenderia seus interesses no mundo colonial, inicialmente circunscritos à África e à Ásia, pela primeira vez aos países latino-americanos. Embora tenha tido como foco a questão balcânica, nesse congresso ficou determinada a criação do Secretariado Sul-Americano (SSA), dedicado exclusivamente aos assuntos da região, em moldes similares a organismos já existentes destinados às questões da Europa central, o mais importante deles até então, Balcãs e Ásia Central, por exemplo. Até a fundação do SSA, a comunicação entre os PCs latino-americanos e a IC era feita através do Partido Comunista Argentino (PCA), que desempenhava, oficiosamente, a função de caixa de correspondência (Mazzeo, 1999, p. 50-51;Pinheiro, 1991, p. 147-148).

A mudança de percepção da IC sobre a importância do continente latino-americano parte do reconhecimento da atuação crescente do imperialismo estadunidense na região, em constante disputa com os capitais britânicos previamente estabelecidos. Desse modo, seria possível desestabilizar o imperialismo britânico, principal inimigo de acordo com a estratégia então seguida pela IC. A América Latina em geral, e o Brasil em especial, serão o terreno privilegiado dessa disputa. Entretanto, o enfoque no continente não veio acompanhado de um esforço para elaborar teoricamente suas principais especificidades históricas. A projeção da via chinesa para o caso brasileiro é o melhor exemplo disso, com a proposta da formação de uma frente ampla nacionalista e anti-imperialista, nos moldes daquela frente composta pelo Partido Comunista Chinês (PCC) e o Kuomintang. Não por acaso, a frente eleitoral posta em prática pelo PCB nos anos seguintes, o Bloco Operário Camponês (BOC), seria designada pelo secretário da Seção Latina da IC, Jules Humbert Droz, como "Kuomintang brasileiro". (Pinheiro, 1991, p. 153-156).

Ora, tal reducionismo é acentuado pela subordinação das diretrizes estratégicas da IC à tese do socialismo em um só país, somado ao desconhecimento completo das peculiaridades históricas dos países coloniais - latino-americanos, principalmente -, e, em alguma medida, pelo eurocentrismo dos membros da IC.A restrição da liberdade desfrutada pelas seções nacionais da IC aumenta pari passu ao avanço da subordinação à tese do socialismo em um só país. Um primeiro passo nesse 
sentido foi a mudança de posição ocorrida entre o IV eV Congressos da IC, dirigida principalmente às possibilidades de aliança entre a classe trabalhadora e a burguesia nos países coloniais. Colocam-se assim os elementos fundamentais da teoria dos quatro blocos, que se aplica ao mecanismo de formação de frentes populares na América Latina. Entretanto, esse era apenas um sinal do que estava por vir no VI Congresso da IC (Mazzeo, 1999, p. 41-42).

OVI Congresso da IC ocorre em um clima de acirramento das disputas em torno da tese do socialismo em um só país, chegando ao ponto da ruptura definitiva entre Stalin e Trotski; este último, principal proponente da tese da revolução mundial.Além disso, o congresso transcorre sob forte impacto da derrota do levante de Xangai. Se por um lado a derrota foi atribuída aos erros de condução da direção nacional, e não às orientações táticas fornecidas pela IC, por outro, a vitória definitiva da tese do socialismo em um só país não levou senão à absoluta obliteração das particularidades históricas dos países coloniais. Nesse congresso se institui a taxonomia oficial, exposta por Bukharin, que dividia os países em três grupos: os países de capitalismo superior, com forças produtivas desenvolvidas e democracia burguesa plenamente estabelecida, países de nível médio, com vestígios feudais e um processo de democratização incompleto, e os semicoloniais, nos quais a luta contra o feudalismo e a realização da revolução democrático-burguesa seria necessariamente uma etapa preparatória para o socialismo (Mazzeo, 1999, p. 47-48).

Essa formulação seria a base daquilo que veio a ser conhecido como "teoria consagrada". Em seus termos, o desenvolvimento histórico das sociedades humanas é apreendido como um processo evolutivo que passaria necessariamente pelas etapas do comunismo primitivo, escravismo, feudalismo, capitalismo e comunismo. Fundamento da tática do bloco das quatro classes, que apregoava a formação de um bloco antifeudal e anti-imperialista entre a classes trabalhadora e setores nacionalistas das burguesias coloniais, a teoria dos cinco estágios promoveu a cristalização de uma estratégia rígida para as seções nacionais dos países latino-americanos. Em detrimento das diretrizes exíguas postas anteriormente, elimina-se por completo as condições responsáveis por fomentar a aparição de análises criativas e originais das realidades locais. Tais formulações tornam-se então incapazes de superar o dilema entre 
o particularismo hipostasiado, isto é, a percepção da particularidade deslocada da universalidade, e a generalização indevida, que lacera totalmente a particularidade histórica de cada formação social (Löwy, 2007, p. 12-14).

Passado o VI Congresso, a I Conferência dos Partidos Comunistas Latino-Americanos, em 1929, detalha os elementos para uma teoria geral da revolução no continente, agora, referenciada na situação mexicana. A transposição esquemática das experiências dos países centrais, ou ainda, de países latino-americanos de configurações históricas sui generis, no bojo da conclusão do processo de estalinização dos PCs, consistiu no passo final para o empobrecimento das visões criativas do processo histórico latino-americano então em curso. Esse processo também culminou na imposição de uma autocrítica a Brandão e no afastamento do primeiro grupo dirigente do PCB, encabeçado por Astrojildo Pereira. Os motivos do afastamento seriam supostos desvios pequeno-burgueses, isto é, o menchevismo, praticado pela organização, incapaz de manter a autonomia da classe trabalhadora no esquema do bloco das quatro classes (Mazzeo, 1999, p. 52-53).

Expostos os traços gerais da gênese e do desenvolvimento das relações do PCB com a IC e da constituição da teoria consagrada, bem como de sua assimilação e imposição para o partido, na próxima seção apresento a crítica formulada por Caio Prado Jr. à teoria consagrada.

\section{Caio Prado Jr. e a crítica à teoria consagrada}

Oriundo de uma rica família de cafeicultores paulistas, Caio Prado Jr. se filiou ao PCB em 1931. Sua atuação mais destacada como militante ocorreu em 1935, quando, após retornar de uma viagem à União Soviética, assumiu a presidência da seção paulista da Aliança Nacional Libertadora (ANL), movimento popular que pretendia formar uma frente antifascista no Brasil. Dissolvida e posta na ilegalidade porVargas, as lideranças da ANL foram perseguidas e presas, rendendo a Caio Prado Jr. dois anos de reclusão; em 1937, foi liberado, pedindo exílio na França. A despeito dessas ocasiões, as divergências veladas em torno da sua orientação teórica, tida como heterodoxa pelo grupo PCB, sempre obstaculizaram seu protagonismo dentro da organização. No seio dessas 
divergências estão o rechaço de Caio Prado Jr. à interpretação e às teses do PCB, teses estas oriundas da importação, por parte do PCB, das diretrizes da IC. Propondo uma interpretação do desenvolvimento histórico brasileiro como capitalista desde o princípio, Caio Prado Jr. iria desafiar a estratégia do PCB, através de uma crítica aos seus fundamentos. Além disso, de modo mais amplo, o autor também dirige sua crítica a toda a tradição historiográfica pregressa, alinhada com a interpretação do feudalismo na realidade brasileira (Mazzeo, 2003, p. 158-159).

A primeira obra em que Caio Prado Jr. veicula essa interpretação capitalista do desenvolvimento histórico brasileiro seria Evolução política do Brasil:ensaio de interpretação materialista da história brasileira ([1933] 2012), livro no qual o autor realiza uma análise de classes da história brasileira do período colonial ao Império empregando tal interpretação como fundamento. No primeiro capítulo da obra o autor trata especificamente da economia colonial, destacando a predominância da grande exploração agrícola e as dificuldades para o estabelecimento da pequena propriedade fundada no trabalho livre; a dura concorrência com a força de trabalho escrava africana, a grande escala produtiva dos empreendimentos necessários às culturas de exportação, a falta de mercados para o escoamento dos produtos, a hostilidade dos povos indígenas e latifundiários etc. A grande exploração, por sua vez, colocaria um grande número de pessoas - trabalhadores livres e escravos - sob comando de um único senhor, em uma escala compatível com as rentáveis culturas de exportação, fazendo frente aos perigos e às adversidades da colônia tropical (Prado Jr., [1933] 2012, p. 24).

Tais elementos são reafirmados e desenvolvidos em sua principal obra Formação do Brasil contemporâneo - Colônia ([1942] 2011), através da tese do sentido da colonização. Consequência do predomínio da grande exploração nas bases econômicas do desenvolvimento do Brasil, a formação econômico-social brasileira deveria atuar como meio de abastecimento de bens primários para as economias metropolitanas. Nos termos do autor, a principal especificidade do capitalismo brasileiro seria apresentar um padrão de desenvolvimento voltado para o mercado externo:

No seu conjunto, e vista no plano mundial e internacional, a colonização dos trópicos toma o aspecto de uma vasta empresa comercial, mais 
completa que a antiga feitoria, mas sempre com o mesmo caráter que ela, destinada a explorar os recursos naturais de um território virgem em proveito do comércio europeu. É este o verdadeiro sentido da colonização tropical, de que o Brasil é uma das resultantes; e ele explicará os elementos fundamentais, tanto no econômico como no social, da formação e evolução histórica dos trópicos americanos. (Prado Jr., [1942] 2011, p. 28)

Contudo, a disciplina militante de Caio Prado Jr., aparentemente inquebrável e inquebrantável, não resistiria diante da estupefação da esquerda brasileira frente ao Golpe Civil-Militar de abril de 1964 e aos acontecimentos que o sucedem. As críticas do autor ao PCB, até o momento silenciadas ou expressas de maneira velada em temáticas transversais - como é caso da crítica à política de reforma agrária e ao apoio ao governo de Juscelino Kubitschek -, se tornariam públicas em A revolução brasileira ([1966] 2014), texto no qual o autor dirige uma crítica à esquerda ao programa do PCB. Para isso, inicia sua exposição com um debate sobre o significado do conceito de revolução, visando dirimir eventuais confusões em torno do tema, já que uma revolução pode ocorrer sem que uma insurreição ocorra; tal seria a dinâmica do processo revolucionário brasileiro. Coutinho (2011b, p. 208-209) destaca a semelhança entre essa formulação de Caio Prado Jr. e os conceitos de via prussiana, formulado por Lênin, e de revolução passiva, elaborado pelo marxista italiano Antonio Gramsci.

No segundo capítulo da obra, nomeado "A Teoria da Revolução Brasileira”, o autor mobiliza uma série de elementos de sua interpretação do desenvolvimento brasileiro - notadamente a tese do sentido da colonização e das origens agrárias da burguesia brasileira -, com o intuito de apresentar suas críticas contra as teorias da revolução até então em voga no PCB.Tais interpretações, que têm seus principais representantes em Nelson Werneck Sodré ([1962] 1964) e Alberto Passos Guimarães ([1963] 1989), afirmam a existência de "feudalismo" ou "restos feudais" como um entrave à consolidação do capitalismo no Brasil'.

O que me interessa em especial é a história das teorias da revolução brasileira que Caio Prado Jr. formula como um dos fundamentos para corroborar sua crítica ao PCB. Correto ao apontar o caráter equivocado

6 É importante notar que mesmo quando Sodré fala em feudalismo, trata-se de um feudalismo à brasileira. Sobre isso, ver: Pinheiro, Curty e Malta (2015). 
dessa tese, Caio Prado Jr. exagera ao atribuir a consolidação dessa linha interpretativa no partido exclusivamente à influência da Internacional Comunista nos anos 1920. Segundo o autor, em linhas gerais, as teorias marxistas do Brasil formuladas entre os anos 1920 e 1960 seriam obra direta da influência da Internacional e, portanto, carregariam tanto falhas teóricas, como de apreensão da realidade concreta. Em seus termos:

A teoria marxista da revolução brasileira, na qual, diretamente ou indiretamente, se inspiraria todo o pensamento político renovador brasileiro, se formulou em seus traços gerais e essenciais na década de 1920, em conjunto com a dos demais países coloniais ou semicoloniais e dependentes. (Prado Jr., [1966] 2014, p. 37)

O equívoco na apreensão da realidade concreta decorre da necessidade de deformá-la para adequá-la ao esquema teórico importado para o Brasil. Nesse procedimento, a abstração assume um papel fundamental. Para Caio Prado Jr. - que, diga-se, para evitar eventuais confusões, difere bastante do procedimento abstrativo empregado por Marx - a abstração é uma teoria formulada a priori para enquadrar a realidade, uma teoria às avessas, indo dos conceitos aos fatos, procurando adequar os últimos aos primeiros. $\mathrm{O}$ autor chega a estabelecer um paralelo entre a natureza dessas formulações sobre o feudalismo e aquelas de Comte e Spencer:

Tem-se a impressão de estar vogando nas águas do velho Augusto Comte com sua famosa Lei dos Três Estados, ou de um Spencer e sua concepção da passagem do homogêneo para o heterogêneo. Isto é, de leis gerais e eternas que enquadrariam a evolução dos fatos históricos em esquemas universais. (Prado Jr., [1966] 2014, p. 34-35)

Como resultado, tem-se um esquema teórico que plana sobre a realidade brasileira e mistifica as condições históricas concretas para a ação política, gerando graves consequências para a práxis revolucionária. O principal alvo da crítica de Caio Prado Jr. são as teorias preconizadas pelo PCB, que caracterizam a revolução no Brasil como antifeudal e anti-imperialista, apontando para a necessidade de suprimir os restos feudais e semifeudais presentes na formação social brasileira. A existência do feudalismo como etapa necessária do desenvolvimento histórico 
resulta da transposição mecânica do esquema da evolução das sociedades humanas em cinco modos de produção - comunismo primitivo, escravismo, feudalismo, capitalismo, comunismo -, inspirado na evolução das sociedades europeias, para a realidade brasileira. Embora existam coincidências e semelhanças, estas não podem ser consideradas dominantes na formação social, o que implicaria a ignorância das verdadeiras condições históricas por parte das teorias da revolução no Brasil.

É, aliás, aquela ignorância da realidade brasileira que tornou tão fácil aos autores da nossa teoria revolucionária aplicarem ao Brasil o esquema consagrado de uma revolução democrático-burguesa destinada a eliminar do nosso país os "restos feudais" ainda nele presentes por atribuição do mesmo esquema. Graças a essa ignorância, não se embaraçaram nossos teóricos com o profundo e chocante contraste entre o que realmente se passava no Brasil e o que eles entendiam que deveria se passar. $\mathrm{O}$ contraste somente se faria sentir na inaplicabilidade da teoria à prática, e nas lamentáveis consequências que isso traria para o processo revolucionário e sua maturação. (Prado Jr., [1966] 2014, p. 39)

A transposição mecânica desses esquemas e a ignorância da realidade brasileira, permitem explicar o alheamento da esquerda às situações políticas revolucionárias. Este seria, para Caio Prado Jr., o caso de 1964; poderíamos, contudo, estender tal análise às condições revolucionárias de 1930. Embora o alvo de sua crítica seja a linha política encaminhada pelo PCB entre os anos de 1944 e 1954, e esta enfatize oVI Congresso da Internacional Comunista, em 1928, como marco da entrada massiva da teoria consagrada no PCB, Caio Prado Jr. desconsidera a existência de uma análise da especificidade nacional nas formulações do partido ao longo dos anos 1920. Consequentemente, a interpretação de Octavio Brandão é desconsiderada como fundador de um marxismo nacional legítimo, e, nesse sentido, a omissão é mais perversa do que a crítica.

A partir deste prognóstico sobre a teoria consagrada, no capítulo seguinte, intitulado "A realidade econômica brasileira", Caio Prado Jr. se propõe a realizar a correção e a revisão dessas formulações, com base em sua interpretação do Brasil. Passo agora à análise da obra de Octavio Brandão, procurando apontar elementos subjacentes à sua análise da realidade que apontem para a especificidade nacional. 


\section{Octavio Brandão e as origens do marxismo nacional}

Egresso do movimento sindical anarquista, e formado em um referencial teórico notadamente positivista, Octavio Brandão percorre a trajetória típica dos pioneiros na construção do movimento comunista brasileiro. Nascido em 12 de setembro de 1896 emViçosa (AL), conhecida região canavieira ao centro do estado, situada nas proximidades do Quilombo dos Palmares,sua paisagem e sua gente serviram de inspiração para romances do colega de classe no primário, Graciliano Ramos (Brandão, 1978, p. 58). É em Viçosa que Paulo Honório, protagonista de São Bernardo ([1934] 2013), adquire propriedade, após fazer fortuna como mascate sertão adentro. Assim como as demais personagens que compõem a trama, os personagens de Graciliano Ramos encarnam trajetórias históricas possíveis para homens e mulheres à época, característica marcante do seu realismo (Coutinho, 2011a) - Brandão poderia facilmente ser um deles.

Tendo cursado farmácia em Recife, Brandão se interessa simultaneamente pelas ciências naturais e históricas. Em sua visão, essas ciências articulam em uma evolução contínua formas de ser vistas como qualitativamente semelhantes, contemplando a totalidade do desenvolvimento histórico-geológico. Em 1917, o autor iniciou uma série de viagens pelas lagoas de Manguaba e do Mundaú e seus canais, para conhecer suas formações geológicas, sua botânica, mas,sobretudo, seu povo. Os registros dessa viagem lhe renderiam seu primeiro trabalho de fôlego, Canais e lagoas ([1919] 2001), no qual o autor descreve a terra e a gente das lagoas de Manguaba e do Mundaú, em Maceió. Abertamente inspirado em Os sertões, de Euclides da Cunha, o livro marca a maturação da visão de mundo de sua juventude, abarcando em um mesmo referencial teórico a terra e a gente das lagoas, e tratando de aspectos geológicos, botânicos, antropológicos e sociais em doze ciclos evolucionários (Lacerda, 2015, p. 15).

Dessa pesquisa, Brandão realizou duas palestras em 1917 em Maceió, nas quais expunha os processos geológicos que haviam produzido as Lagoas do Mundaú e de Manguaba. Tais processos indicavam como os sedimentos acumulados nas lagoas e em seus canais de ligação com o mar eram indícios da possibilidade de descoberta de petróleo comercializável. Sua explicação científica para a formação das lagoas, calcada 
na geologia, desagradou profundamente a Igreja Católica, extremamente influente no meio social local, ao passo que seu posicionamento político nacional-popular desagradou profundamente as elites locais, alinhadas com o imperialismo ${ }^{7}$.

Participando da luta pela redução da jornada de trabalho e por aumentos salariais com camponeses e operários de Alagoas, Brandão seria alvo de perseguição policial. A publicação de um artigo no jornal $A$ semana social, com posicionamento contrário à entrada do Brasil na Primeira Guerra Mundial, uma guerra imperialista, levaria ao fechamento do jornal por ordem do governo federal e agravaria esse quadro. Após ser cercado e escapar pelos fundos da redação do jornal, o autor seria jurado de morte por um pistoleiro que, caso o executasse, receberia o cargo de chefe de polícia (Moraes, 2014, p. 16-17).

Escondido em um navio, Brandão fugiria para o Rio de Janeiro em 1919, onde assume a linha de frente das lutas sindicais, escrevendo artigos na imprensa, realizando conferências para os trabalhadores, panfletando nas portas de fábrica e proferindo discursos em comícios (Del Roio, 2004, p. 119). Chegando ao Rio de Janeiro, Brandão participa da "primeira fundação" do PCB, em junho de 1919, mas, com a dissolução da organização, não pende imediatamente para o lado dos bolchevistas. A adesão de Brandão ao PCB estaria hipotecada à constatação de que a crise do segundo ciclo de greves resultou das debilidades organizativas do anarcossindicalismo. Era preciso uma forma organizativa capaz de enfrentar os métodos policiais empregados pela burguesia, e essa forma era o bolchevismo ${ }^{8}$. Ao ingressar no PCB, Brandão foi designado para

7 Nas palavras do autor: "Já é tempo de abrirmos os olhos para as nossas riquezas e confiarmos antes nelas, do que nos clássicos empréstimos indecentes ou nas promessas falazes dos nossos pretendidos irmãos latinos ou amigos britânicos, que afinal não passam de sanguessugas insaciáveis." (Brandão, [1919] 2001, p. 133, grifo nosso).

8 Sobre a perseguição política aos trabalhadores ao longo da Primeira República, ver Pinheiro (1991, capítulo 5). Nesse capítulo, o autor destrincha os métodos policias de repressão à classe trabalhadora, destacando a deportação e o desterro para campos de concentração, como o de Clevelândia, no Oiapoque. Os trabalhadores muitas vezes eram presos por vadiagem ou escolhidos a esmo entre os desafetos pessoais das autoridades policiais. As condições de transporte até o campo, assim como as condições desumanas de vida testemunhadas, faziam com que, na prática, o desterro fosse uma sentença de morte. 
as tarefas de formulação teórica, elaborando uma defesa do movimento comunista internacional e da Revolução Russa ${ }^{9}$ (Konder, 2009, p. 181).

Resulta da execução dessa tarefa a redação de Rússia proletária (1923), obra na qual é feita uma apaixonada defesa da Revolução Russa, marcando a transição do autor para o marxismo. Publicada pelo jornal $A$ voz cosmopolita, a obra era dividida em duas partes. A primeira tratando dos indígenas, de acordo com o autor, elementos pré-históricos; e a segunda dos elementos históricos, subdivididos em quatro ciclos evolutivos: primitivo, medieval, medievo-moderno e moderno. O quinto, a Revolução Comunista, ainda estava por ocorrer, mas já estava previamente estabelecida. Com exceção do último, a ditadura do proletariado, todos os demais ciclos possuem uma divisão entre classes exploradoras e classes exploradas, que, na perspectiva do autor, são as contradições moventes da evolução histórica brasileira. Em Rússia proletária, os conceitos de classe social e imperialismo passam a dividir espaço com os de povo e nação. Contudo, permanecem a aplicação dos ciclos evolutivos e a visão monista da realidade histórico-social, trazendo embrionariamente a interpretação apresentada em Agrarismo e industrialismo.

Outra contribuição importante associada à atuação de Brandão é a primeira tradução integral de O manifesto comunista, publicada em 1924 no jornal $A$ voz cosmopolita. O trabalho de difusão do marxismo realizado por Brandão raramente é lembrado como um aspecto importante do seu trabalho. Mesmo Konder, pouco simpático ao marxista alagoano, reconhece que:"Ao que tudo indica, nenhum outro marxista brasileiro, naquele momento, dispunha de uma bagagem de conhecimento comparável à Brandão" (Konder, 2009, p. 182). Algumas das escassas leituras, disponíveis apenas em língua estrangeira, eram: Miséria da filosofia, $O$ Anti-Dühring, Ludwig Feuerbach e o fim da filosofia clássica alemã, As lutas de classe na França, e o resumo de O capital, de Carlos Cafiero.

Por último, vale destacar a influência decisiva de Lêninna adesão de Brandão ao marxismo, através de textos como O Estado e a revolução e Imperialismo, estágio superior do capitalismo. Tal influência transpareceria inclusive no título de Agrarismo e industrialismo, que, antes mesmo do

9 Sua entrada na organização em fins de 1922 foi festejada por Astrojildo Pereira, que declarou em um discurso aos operários que “"um homem que vale por 10', havia ingressado no partido” (Dulles, 1977, p 151). 
termo marxismo-leninismo ser empregado de maneira rotineira, já se pretendia um ensaio marxista-leninista de interpretação histórica ${ }^{10}$. Perseguido pela polícia política no estado de sítio de Arthur Bernardes, escondido na casa de um camarada, Brandão acompanhava atentamente o levante tenentista de 1924, que começaria localmente para então ganhar magnitude nacional, originando a Coluna Prestes:

Na clandestinidade, Octavio Brandão, a 28 de julho de 1924, se encontrava na casa do jornalista Rodolfo Mota Lima, quando chegaram ao Rio as notícias de que as tropas de Isidoro tinham evacuado São Paulo. Rodolfo Mota Lima entra pela casa completamente desesperado pela notícia da derrota. Brandão acabara de ler uma tradução francesa de Imperialismo, estágio superior do capitalismo; sentado ao fundo da sala de jantar, começou a redigir um estudo a respeito da revolta de 1924, conforme a interpretação marxista. (Dulles, 1977, p. 222)

\subsection{Uma interpretação marxista-leninista da realidade brasileira}

Sob impacto da irrupção do segundo levante tenentista e da Coluna Prestes, Brandão iniciou imediatamente a redação daquilo que viria a se tornar o primeiro ensaio marxista de interpretação da realidade nacional. Seu objetivo era compreender o significado das revoltas tenentistas através de uma mirada totalizante, recorrendo para isso ao referencial teórico "marxista-leninista". A influência do movimento dos tenentes transparece em seus primeiros parágrafos: "Enquanto a batalha se prolonga pelo interior, através de guerrilhas, procuraremos fazer a análise dessas lutas sob o ponto de vista do marxismo-leninismo" (Brandão, [1926] 2006, p. 25).

Entretanto, Agrarismo e industrialismo não se limita unicamente à análise teórica de seu objeto, a formação social brasileira, trazendo à tona também uma convocatória à ação da classe trabalhadora na transformação

10 Os comentadores divergem sobre o primeiro uso da expressão marxismo-leninismo. Enquanto Moraes (2007, p. 41-43) afirma que Deborin empregou pela primeira vez a expressão em março de 1928, e que Stalin só a utilizou em 1930, Bianchi (2012, p. 138) afirma que a expressão foi utilizada por Zinoviev, em 1927, nas teses sobre a revolução chinesa, e Stalin só a empregaria em 1928. O que interessa aqui é que todas as datas são posteriores a Agrarismo e industrialismo, endossando o uso "pioneiro" do termo por Brandão. 
desse objeto. Desse modo, o texto oscila entre um ensaio de interpretação histórica e um panfleto de agitação política. Seu estilo é seco e direto, procurando com isso atingir seu público alvo, as massas trabalhadoras e a pequena burguesia urbana, mas "nem por isso deixava de ser confuso, disperso e pretensioso" (Bianchi, 2012, p. 139). A estrutura argumentativa por enumeração, através do levantamento de sucessivos fatos que corroboram a tese do autor para explicar o desenvolvimento social brasileiro, obstaculiza a leitura, causando descontinuidades ao longo da exposição do argumento. Isso se relaciona à forma como Agrarismo e industrialismo foi redigido. A primeira parte da obra, que contém seus elementos fundamentais, foi terminada em agosto de 1924 e serviu como base para a formulação das teses do II Congresso do PCB ${ }^{11}$, em 1925. As duas últimas partes, que complementam a discussão anterior, foram escritas respectivamente em 1925 e 1926. A ausência de uma exposição clara de suas teses e a construção da argumentação por enumeração, levantando fatos e dados aparentemente sem nenhuma conexão interna para dar volume ao argumento, obscurecem muitos pontos da obra.

O método marxista-leninista utilizado por Brandão foi duramente criticado por seus interlocutores. Aristides Lobo, ao comentar Agrarismo e industrialismo no jornal da Liga Comunista Brasileira (LCB), organização trotskista fundada no final dos anos 1920, considera que a obra teria sido "a tentativa mais séria, mais meticulosa e mesmo mais heroica" (Lobo, [1931] 2015, p. 75) de tratar da situação brasileira até então, mas, ao mesmo tempo "a mais antimarxista e desastrosa [...] um bazar de monstruosidades teóricas” (Lobo [1931] 2015,p. 76). Entre seus comentadores, Konder (2009, p. 183) insiste no mecanicismo do pensamento do autor, que compreende a dialética de Marx como o emprego da tríade tese-antítese-síntese para a explicação do desenvolvimento histórico, tendo um entendimento da dialética que mais se aproxima de Aristóteles do que de Marx. Outros, como Moraes (2006, p. 15), consideram injusto punir Brandão por esses equívocos, dadas as condições de sua reflexão, destacando o tratamento acertado de Brandão das questões especificamente histórico-concretas. Nesses momentos, até mesmo

11 Mesmo tendo servido de base para a redação das teses do II Congresso do PCB, não há qualquer menção a Agrarismo e industrialismo em $A$ formação do PCB, de Astrojildo Pereira. Narrando o II Congresso, o autor resume o argumento de Brandão sem citar a obra (Pereira, [1962] 2012, p. 92). 
Konder é forçado a assumir, aparentemente a contragosto, a presença nas análises de Brandão de "algumas observações empíricas não desprovidas de interesse a respeito da sociedade brasileira" (Konder, 2009, p. 184).

Em que pese à compreensão mecânica da dialética e uma base filosófica monista e evolucionista, herdada de sua formação prévia no pensamento positivista - o que compromete sua análise em níveis de abstração mais elevados -, indubitavelmente, Brandão avança na análise da especificidade brasileira. Isso é válido tanto para o marxismo no Brasil, que dava os primeiros passos nesse debate com a contribuição de Brandão, quanto para o pensamento social brasileiro, no qual imperava o determinismo naturalista e o racismo associados ao darwinismo social dominante nesse momento ${ }^{12}$ (Silva, 1997, p. 44).

Brandão parte do predomínio histórico das forças agraristas, ora designadas como feudais ou semifeudais, ora designadas como uma burguesia agrária, sendo a terminologia empregada oscilante ao longo do texto e das edições da obra. Tais forças consolidar-se-iam através do tripé: Igreja Católica, Exército e Estado. Externamente, associar-se-iam ao imperialismo britânico - primeiro, por intermédio de Portugal, e depois, passando à dominação direta britânica. Destaca-se o papel do imperialismo na análise como ponto que diferencia Brandão da teoria consagrada. Enquanto na análise de Brandão o imperialismo é um fator que atua apenas posteriormente, conferindo prioridade e maior autonomia aos determinantes internos do processo histórico, essa relação aparece invertida na teoria consagrada. Para esta última, o imperialismo atua como fator determinante da dinâmica interna das formações sociais coloniais. Ao longo do Império e da República, o domínio britânico seria estabelecido pelo endividamento do Estado com a banca inglesa, tornando o Brasil uma colônia dos capitais ingleses. Os empréstimos, as finanças e concessões eram dominados pelos Rothschild, aliados dos agrários. Em troca,

12 Leandro Konder afirma que "Até preconceitos raciais emergem no pensamento de Brandão. Ele lamenta que o Brasil seja prejudicado pela proliferação de 'intermediários'. Os intermediários - explica - são 'tipos que, geralmente, não possuem as qualidades dos extremos, tendo só defeitos de ambos” (Konder, [1988] 2009, p. 185). Angelo José da Silva, por outro lado, diverge: "Os estudos baseados na raça, no meio físico-geográfico etc., embora apareçam em Agrarismo e industrialismo, não compõem a tônica do trabalho. Ou seja, no mínimo afirmo que o trabalho em pauta é uma ruptura com tudo aquilo que havia sido feito até então, como tentativa de interpretação da sociedade brasileira" (Silva, 1997, p. 44). 
davam-lhes cargos de diretoria nessas companhias. Além disso, politicamente, tratavam de impor a agenda britânica de desenvolvimento para o Brasil, naqueles anos, sintetizada no Relatório Montagu ${ }^{13}$.

Para Brandão, dominado pelo "agrarismo econômico [...] o Brasil tinha de ser dominado pelo agrarismo político, consequência direta daquele" (Brandão, [1926] 2006, p. 36). O agrarismo político é a dominação política dos grandes proprietários e o emprego do Estado como uma ferramenta "em proveito egoísta, individual, com o fim de multiplicar seus lucros, embora o Estado e povo sejam sacrificados" (Brandão, [1926] 2006, p. 28). Todas as decisões políticas do Estado eram voltadas para o interesse da burguesia agrária: o endividamento externo para financiar a política da valorização do café, o emprego das desvalorizações cambiais como mecanismo de sustentação da renda dos cafeicultores e a ausência de tributos que incidissem sobre a propriedade fundiária.

A Primeira Guerra Mundial abalaria o domínio britânico, empurrando as burguesias britânica e estadunidense para uma guerra mortal pela supremacia no mercado dos países coloniais, em especial pela supremacia nas praças brasileiras. Esse é um ponto que aproxima Brandão das leituras propostas pela IC ao longo do período, sobretudo a partir do V Congresso da organização, realizado no ano da redação inicial de Agrarismo e industrialismo. No entanto, é importante considerar que tal aproximação ocorre apenas em níveis de abstração mais elevados, já que, à diferença da IC, o autor procura respaldar essas teses na realidade brasileira. Isso é patente na construção de uma periodização para essa disputa no âmbito da formação social brasileira, que, por isso, toma como referência o período do Império:

Desenha-se, pois, uma luta mortal, com fluxos e refluxos, entre os dois grandes imperialismos: 1822-1891 supremacia da Inglaterra, 1914-1922 supremacia dos Estados Unidos, 1923-1924 rivalidade imperialista anglo-americana, pendendo a balança para o lado da Inglaterra. (Brandão, [1926] 2006, p. 94)

Associadas ao imperialismo estadunidense, emergem forças indus-

13 Missão econômica inglesa (1923-1924) enviada pelos Rothschild, e dirigida por Lord Montagu, para avaliar as condições financeiras do Brasil e as garantias ao capital estrangeiro, visando concretizar a rolagem da dívida externa. 
trialistas. Em outras palavras, uma burguesia industrial de base urbana e politicamente liberal. Até então sufocadas pela hegemonia agrarista, a burguesia urbana se apresentou, em determinado momento, como uma força política apta a disputar os rumos do Estado agrário e a definição da política econômica, pautada exclusivamente pelos cafeicultores. Contudo, para Brandão, a virada da rivalidade imperialista para o lado britânico no plano externo e a resistência das forças agrárias no plano interno, com o governo de Arthur Bernardes, contribuíram para a desorganização política da burguesia industrial.

Outro ator político fundamental é a pequena-burguesia urbana e rural. Segundo Brandão, "Há uma numerosa pequena-burguesia - rural, comercial, industrial, burocrática - procurando sempre conciliar: nos campos, o interesse dos colonos-servos com os fazendeiros; nas cidades os interesses dos operários com o dos grandes burgueses industriais" (Brandão, [1926] 2006, p. 33). Nos campos e nas cidades, a pequena-burguesia demanda a melhoria de sua situação econômica e maior participação política. No primeiro plano, há o processo de proletarização dessa fração de classe, como resultado das sucessivas desvalorizações cambiais para garantir a renda de exportação dos cafeicultores, o que nos marcos de uma economia agrário-exportadora, com alto coeficiente de importação, provoca uma elevação do custo de vida. Essas condições agravam também problemas como a falta de infraestrutura urbana, saneamento básico e o déficit habitacional ${ }^{14}$.

No plano político, há “[a] desilusão da pequena-burguesia, de obter melhorias pelos canais competentes; isto é, pela via legal, jurídica, pacifista, reformista" (Brandão, [1926] 2006, p. 26), apontando para baixa permeabilidade do sistema político democrático às demandas dos diversos setores sociais e a impossibilidade de conciliação. Nas palavras do autor: "Desagrega-se a pequena-burguesia. Economicamente rolando para a miséria. Politicamente, hesitando entre o proletariado e a grande burguesia” (Brandão, [1926] 2006, p. 143). Isso levaria à gradual radicalização

14 Mattos (2009, p. 43) apresenta uma tabela que aponta para um descolamento do índice de salários e de custo de vida após 1917, tomando 1914 por ano base. O índice se desloca de 128, em 1917, para 167, em 1921. O autor conclui: “Trabalhava-se muito, ganhava-se pouco e pagava-se caro para viver mal. As descrições dos locais de moradia dos trabalhadores no início do século conduzem-nos a realidades miseráveis, insalubres e superpovoadas" (Mattos, 2009, p. 43). 
política dessa fração, algo atestado pelos levantes tenentistas de 1922 e 1924, e à deflagração do tenentismo como movimento político nacional.

$\mathrm{O}$ incipiente desenvolvimento industrial origina um proletariado urbano numericamente reduzido, que, de acordo com Brandão, procurará se organizar politicamente. A parte final do livro apresenta uma história do proletariado brasileiro, dividida em três partes: “1"a da escravidão dos índios e dos negros. $2^{a}$, A história da servidão do trabalhador rural [na primeira edição: proletário rural]. $3^{\text {a }}$, a história do salariado [proletariado].” (Brandão, [1926] 2006, p. 113).

A tarefa dos intelectuais revolucionários nesse campo seria tratar da segunda e da terceira etapas, à medida que os historiadores burgueses "tem-se ocupado da primeira parte, embora atenuando as cores"15 (Brandão, [1926] 2006, p. 113). A luta do trabalhador rural e de sua servidão seria ainda uma página obscura à espera de um historiador. Já a história do proletariado industrial, abordada por Brandão, tem seu início nas greves ocorridas após 1889, com a chegada dos imigrantes europeus, trazendo a semente anarquista.

Esse processo organizativo atinge seu ápice com as greves operárias de 1917-1919, marco do esgotamento do movimento anarquista e da primeira fundação do PCB. Nos anos seguintes teria lugar uma disputa ideológica entre comunistas e anarquistas, permitindo compreender que: "Eram necessários uma nova ideia e um novo método. Assim, em 7 de novembro de 1921, quarto aniversário da revolução russa, doze camaradas lançaram as bases do Partido Comunista do Brasil, fundado em março de 1922" (Brandão, [1926] 2006, p. 116).

Ao longo dos anos 1920, juntamente ao processo de organização política do proletariado, ocorreria o fortalecimento do PCB no movimento sindical, soldando um vínculo entre o partido e a classe trabalhadora. O autor narra essa evolução ao longo de sete ciclos evolutivos que se desenrolam em uma dialética mecânica.

15 Ainda a esse respeito:“Criemos uma tradição revolucionária, escrevendo a história das lutas proletárias no Brasil, a história dos militantes e mártires, das vitórias e derrotas, das ideias e sentimentos da massa e da vanguarda e, principalmente, extraindo as devidas lições táticas. Estudemos a fundo o Brasil em seus mil aspectos - econômico, político, moral e mental, histórico e etnográfico, físico e social - porque é no Brasil que temos de realizar a obra do leninismo." (Brandão, [1926] 2006, p. 130). 
Em suma, na perspectiva do autor ocorreria um embate fundamental entre, de um lado, as forças agrárias conservadoras, associadas ao imperialismo britânico e, de outro, as forças progressistas, reunidas em um bloco encabeçado pela burguesia industrial, seguida pela pequena-burguesia, pelo proletariado e por trabalhadores rurais, associados ao imperialismo estadunidense. Essa ordem agrária teria como elemento central de sua desagregação o movimento insurrecional tenentista e a radicalização política da pequena-burguesia, diante da desorganização e debilidade econômica e política da burguesia industrial.Apesar das debilidades organizativas, o proletariado deveria tomar partido nas revoltas pequeno-burguesas em curso, tanto na segunda revolta tenentista (nos anos de redação do livro, ainda em aberto), quanto na organização de uma terceira revolta, caso esta porventura viesse a ocorrer.

\subsection{A caracterização democrática pequeno-burguesa da revolução brasileira}

Como sua "imagem do Brasil" articula o trânsito histórico no país, a análise da formação social feita por Brandão já contém os contornos fundamentais da análise da revolução brasileira: seu conteúdo democrático-burguês antifeudal e anti-imperialista, a caracterização da burguesia industrial como politicamente liberal e a radicalização política da pequena-burguesia como força motriz disruptiva da ordem social agrarista. O proletariado deveria inserir-se nesse processo e pautá-lo sobretudo através da radicalização da pequena-burguesia, a qual tornaria o conteúdo do processo socialista. A revolução democrática pequeno-burguesa aparece não como etapa necessária ao processo revolucionário, previamente enquadrada em um esquema abstrato, mas como sua antessala, demovendo entraves às lutas de classes nos marcos de uma formação econômico social concreta. Desse modo, afasta-se qualquer possibilidade de inclusão de Brandão naquilo que Caio Prado Jr. designou como teoria consagrada, distanciando-se "das teses a respeito da história latino-americana que começavam a ser esboçadas pela internacional” (Bianchi, 2012, p. 139).

Ainda no final de Agrarismo e industrialismo, na parte cuja redação foi concluída em 1926, Brandão considera que a possibilidade de uma revolução proletária está hipotecada à realização de um terceiro levante 
tenentista. Nos moldes da tríade tese-antítese-síntese o autor atribui à tese o primeiro levante tenentista, ainda local; o segundo levante, já nacional, seria sua antítese; e uma terceira revolta, protagonizada pelo proletariado, seria sua síntese. Dessa análise o autor deduz algumas diretrizes táticas:

Lutemos por impelir a fundo a revolta pequeno-burguesa, fazendo pressão sobre ela, transformando-a em revolução permanente no sentido marxista-leninista, prolongando-a o mais possível, a fim de agitar as camadas mais profundas das multidões proletárias e levar os revoltosos às concessões mais amplas, criando um abismo entre eles e o passado feudal. Empurremos a revolução da burguesia industrial - [...] - aos seus últimos limites, a fim de, transposta a etapa da revolução burguesa, abrir-se a porta da revolução proletária comunista. (Brandão, [1926] 2006, p. 133)

Além de Agrarismo e industrialismo, Brandão aborda o tema para o III Congresso do PCB (1928-1929). Em O proletariado perante a revolução democrática pequeno-burguesa ([1928] 1985), publicado no número 8 da revista Autocrítica, órgão de discussão para o III Congresso do $\mathrm{PCB}^{16}$, a caracterização da revolução alinhavada em Agrarismo e industrialismo é aprofundada. Nesse texto, além de detalhar a caracterização do conteúdo e das tarefas da revolução, reafirma-se a concepção de revolução permanente, através do encadeamento da etapa pequeno-burguesa ao seu desfecho socialista.

Brandão separa inicialmente dois complexos complementares de problemas: “1. ${ }^{\circ}$ ) O problema da revolução democrática pequeno-burguesa desencadeando-se em um país semicolonial na atual fase do capitalismo imperialista; $2{ }^{\circ}$ ) o problema da revolução proletária nesse mesmo país” (Brandão, [1928] 1985, p. 121). Uma revolução proletária vitoriosa no Brasil seguiria a via pequeno-burguesa, desencadeada por uma terceira revolta tenentista:

[...] a revolução proletária parece-nos ser a consequência natural de uma revolução democrática pequeno-burguesa, nascida de uma terceira revolta,

16 A versão de O proletariado perante a revolução democrática pequeno-burguesa à que faço referência ao longo desta seção encontra-se como apêndice do livro de Michel Zaidan (1985), PCB (1922-1929): na busca das origens de um marxismo nacional. 
agravada por uma crise cafeeira [...] e radicalizada pelo combate ao imperialismo e, principalmente, pela ação das massas urbanas e rurais, armadas. (Brandão, [1928] 1985, p. 122)

Para o autor é fundamental a inserção do proletariado nesse processo. O proletariado deveria se preparar desde já para a terceira revolta, conseguindo, assim, atuar de modo politicamente independente ao longo do processo, sem ir a reboque do movimento pequeno-burguês:

Por conseguinte, o problema atual é o da atitude do proletariado e do seu partido diante da revolução democrática pequeno-burguesa, prelúdio fugaz da revolução proletária, se o proletariado e o seu partido se prepararem de fato, orgânica e ideologicamente, com a devida antecedência, isto é, desde já. (Brandão, [1928] 1985, p. 122-123)

Mas, para que o proletariado desfrutasse de potencial de ação autônoma, era preciso elaborar uma política de alianças consequente com tal objetivo estratégico. Lênin é influente nessa formulação, na medida em que a política de alianças foi fundamental no processo revolucionário russo. De acordo com o autor:

[...] nenhuma dúvida é possível: segundo as próprias palavras de Lênine num de seus livros fundamentais de tática, o proletariado industrial e o seu partido têm de procurar aliados não somente no período posterior a revolução proletária, como igualmente no período anterior (é o nosso caso). Não importa que sejam aliados hesitantes, pouco seguros. Temos de procurá-los: eis um de nossos problemas fundamentais. (Brandão, [1928] 1985, p. 124)

O autor considera então a necessidade de estabelecer alianças com a burguesia industrial liberal e a pequena burguesia radicalizada, com o intuito de formar um bloco antiagrarista e, assim, arquitetando a tomada do Estado agrário. A formação de uma frente única composta por forças inimigas do Estado agrário vem acompanhada de uma série de diretrizes táticas que prezam pela ação paralela do proletariado na elaboração de formas independentes de organização e atuação. A tarefa do proletariado seria transformar a revolução pequeno-burguesa em revolução proletária: 
[...] o melhor modo de trabalharmos pela revolução proletária é procurarmos os meios de transformar a revolução democrática pequeno-burguesa em revolução proletária. [...] Um dos nossos trabalhos fundamentais deve consistir em lutar para que a revolução democrática pequeno-burguesa seja colocada num plano inclinado que a faça rolar no sentido da profundeza da revolução operária. (Brandão, [1928] 1985, p. 131)

Apresentando um fundamento concreto para identificar as especificidades do caso brasileiro, a formulação de Brandão seria rechaçada pela III Internacional Comunista (IC) após a derrota do levante de Xangai e da realização doVI Congresso da organização. Com a intervenção do Secretariado Sul-Americano (SSA), após a I Conferência dos Partidos Comunistas Latino-Americanos, a IC, pela primeira vez, impunha suas rígidas diretrizes de interpretação histórica ao PCB. Rompia-se a negligência salutar da IC com o partido, o que permitiu o desenvolvimento de uma interpretação evidentemente limitada, mas que tinha como seus maiores méritos a criatividade, a originalidade e a familiaridade com as especificidades nacionais. Em seu lugar foi posta uma teoria tão ou mais limitada, e completamente alheia às especificidades histórico-concretas do país ${ }^{17}$ (Antunes, 1995, p. 30-31; Zaidan, 1985, p. 50).

Através da intervenção do SSA no Brasil, Brandão e outros integrantes da Comissão Central Executiva (CCE), como Astrojildo Pereira, foram afastados e acusados de menchevismo após o III Congresso do PCB em 1928/1929. Com o afastamento, Brandão seria apagado da memória do partido.A obliteração dessas formulações sobre a particularidade do país, promoveram o divórcio dos comunistas com a realidade brasileira. Exilado na União Soviética em 1930, Brandão permaneceria isolado mesmo após retornar ao Brasil, vivendo como um exilado dentro do seu próprio país. O autor se afasta definitivamente do PCB em 1957. Falecendo em 1980, tais anos marcariam a retomada do estudo da obra de Brandão e o início de sua reabilitação intelectual ${ }^{18}$.

17 Lobo ([1931] 2015, p. 76) declara que:"Condenado o 'Agrarismo e industrialismo'como desvio menchevista, nem por isso se tratou de fazer coisa melhor. Apenas um outro documento, reeditando velhos erros oportunistas, tem surgido para tornar ainda mais confusa a situação, para obscurecer ainda mais o espírito da classe operária e da massa do partido".

18 Nos anos 1980, com a emergência da classe trabalhadora como um ator político relevante no processo de redemocratização, coloca-se como questão a história da 


\section{Considerações finais}

A crítica à teoria consagrada de Caio Prado Jr. atinge Octavio Brandão? Como procurei argumentar ao longo do texto, a crítica de Caio Prado Jr. atinge, apenas parcialmente a reflexão de Octavio Brandão. Isso porque, embora Brandão tente enquadrar o desenvolvimento histórico brasileiro em um esquema previamente estabelecido, sua análise possui um profundo enraizamento na realidade nacional, atingindo sua especificidade através de sua teoria da revolução democrática pequeno-burguesa.Além disso, essas formulações de Brandão não eram apenas resultado de uma negligência, é verdade que salutar,por parte da III Internacional Comunista em relação ao PCB. Era, ao mesmo tempo, um esforço para suprir as carências teóricas da organização, em grande parte decorrentes da ausência de uma tradição marxista previamente estabelecida ou de auxílio da IC. Isso é corroborado, inclusive por depoimentos de militantes trotskistas contemporâneos a Brandão, que, a despeito de serem antípodas na disputa pelos rumos do movimento operário ao final dos anos 1920, concordam com a superioridade do argumento de Brandão ${ }^{19}$.

Exatamente porque Brandão procura apreender a especificidade da revolução brasileira, pode ser considerado um pioneiro nesse debate. Embora seu pensamento apresente algum esquematismo, sobretudo nos níveis de abstração mais elevados, não pode de modo algum ser caracterizado como uma teoria importada, contribuindo de fato para a formação de uma tradição marxista autóctone. Brandão realiza um esforço hercúleo no sentido do estabelecimento de uma teoria da revolução enraizada na realidade brasileira; isso, através de uma caracterização de elementos como a economia colonial, sua transição para o capitalismo, as classes sociais, o

classe trabalhadora brasileira e seu papel político na história do país. No bojo desse processo surgem diversos estudos sobre o movimento operário da Primeira República e sobre a classe trabalhadora brasileira. Sobre isso, ver Costa (2014,p. 135-138) e Moraes (2006, p.17-18), especificamente para a avaliação da obra de Brandão nesses marcos.

19 A disputa entre os integrantes do PCB e os militantes trotskistas no final dos anos 1920, não só marca a ocorrência do primeiro debate interno na esquerda brasileira, como também origina a primeira controvérsia em torno das interpretações marxistas sobre a realidade brasileira. Nesse sentido, cabe ressaltar que tal debate corrobora a tese sobre a fundação de uma reflexão marxista sobre a realidade nacional ainda nos anos 1920. Sobre esse tema, ver Pinheiro (2018). 
Estado e a política. Sua riqueza teórica foi suficiente para suscitar debates internos e externos ao PCB. Internamente, a teoria consagrada passaria a vigorar no $\mathrm{PCB}$ em resposta às formulações de Brandão sobre a revolução brasileira, perdurando até a tentativa de Nelson Werneck Sodré de retomá-la sobre bases nacionais. Externamente, a contribuição de Brandão suscita o posterior debate entre o PCB e as organizações trotskistas à época recém-fundadas.

Com todas as deficiências e excentricidades teóricas, é um fato incontornável, com o enorme respeito devido à contribuição pradiana, que Octavio Brandão é o primeiro marxista brasileiro; isso a contragosto daqueles que defendem que Caio Prado Jr. é o grande fundador de uma tradição marxista brasileira.A polêmica proposta serve para destacar que o critério para fundar uma tradição de pensamento revolucionário nacional inspirada em Marx não é uma leitura teoricamente sofisticada da realidade brasileira, embora isso certamente auxilie a orientação da prática política. $\mathrm{O}$ que funda uma tradição de pensamento marxista autóctone é sim a intenção de captar a peculiaridade do desenvolvimento da realidade brasileira para transformá-la a partir da ação política da classe trabalhadora. Portanto, ao responder essa pergunta, evidencia-se a necessidade de se repensar os parâmetros adotados para a construção da história do marxismo no Brasil, aparando as arestas para uma reapreciação do legado teórico de Octavio Brandão.

\section{Referências}

ANTUNES, Ricardo. Os comunistas no Brasil: as repercussões do VI Congresso da Internacional Comunista e a primeira inflexão stalinista no Partido Comunista do Brasil (PCB). Cadernos do AEL, Campinas, n. 2, p. 12-34, 1995.

ARICÓ, José. O marxismo latino-americano nos anos da Terceira Internacional. In: HOBSBAWM, Eric (Org.). História do Marxismo - volume VIII: o marxismo na época da Terceira Internacional: o novo capitalismo, o imperialismo, o terceiro mundo. Rio de Janeiro: Paz e Terra, p. 409-460, 1987.

BANDEIRA, Luiz Alberto Moniz. O ano vermelho: a Revolução Russa e seus reflexos no Brasil. Rio de Janeiro: Civilização Brasileira, 2017.

BATALHA, Carlos Henrique de Moraes. A difusão do marxismo e os socialistas brasileiros na virada do século XIX. In: MORAES, João Quartim (Org.). História do marxismo no Brasil. Vol. 2 - Os influxos teóricos. Campinas: Editora Unicamp, p. 9-42, 2014. 
BIANCHI, A. Octavio Brandão e o Confisco da Memória: nota à margem da história do comunismo brasileiro. Crítica Marxista, São Paulo, n. 34, p. 133-149, 2012.

BRANDÃO, Octavio. Rússia proletária. Rio de Janeiro:Voz Cosmopolita, 1923.

BRANDÃO, Octavio. Combates e batalhas. Memórias. $1^{\circ}$ volume. São Paulo: Alfa-Ômega, 1978.

BRANDÃO, Octavio. O proletariado perante a revolução democrática pequeno-burguesa.In: ZAIDAN, Michel. PCB (1922-1929): na busca das origens de um marxismo nacional. São Paulo: Global, p. 121-132, 1985. (Original publicado em 1928)

BRANDÃO, Octavio. Canais e lagoas. Maceió: EDUFAL, 2001. (Original publicado em 1919)

BRANDÃO, Octavio. Agrarismo e industrialismo: ensaio marxista leninista sobre a revolta de São Paulo e a guerra de classes no Brasil - 1924.2 edição. São Paulo: Anita Garibaldi, 2006. (Original publicado em 1926)

COSTA, Emília Viotti da. A nova face do movimento operário na Primeira República. In: COSTA, Emília Viotti da. A dialética invertida e outros ensaios. São Paulo: Editora Unesp, p. 135-156, 2014.

COUTINHO,Carlos Nelson. Graciliano Ramos. In: COUTINHO, Carlos Nelson (Org.). Cultura e sociedade no Brasil: ensaios sobre ideias e formas. $3^{a}$ edição. São Paulo: Expressão Popular, p. 141-194, 2011a.

COUTINHO, Carlos Nelson. A imagem do Brasil na obra de Caio Prado Jr. In: COUTINHO, Carlos Nelson (Org.). Cultura e sociedade no Brasil: ensaios sobre ideias e formas. São Paulo: Expressão Popular, p. 201-220, 2011 b.

DEL ROIO, Marcos. Octávio Brandão nas origens do marxismo no Brasil. Crítica marxista, São Paulo, v.1, n.18, p.115-132, 2004.

DULLES, John Watson Foster. Anarquistas e comunistas no Brasil (1900-1935). $2^{a}$ edição. Rio de Janeiro: Nova Fronteira, 1977.

GUIMAR ÃES, Alberto Passos. Quatro séculos de latifúndio. Rio de Janeiro: Paz e Terra, 1989. (Original publicado em 1963)

KONDER, Leandro. A derrota da dialética: a recepção das idéias de Marx no Brasil, até o início dos anos trinta. Rio de Janeiro: Campus, 2009.

LACERDA, Felipe Castilho. A transição de Octávio Brandão ao Marxismo: os livros Canais e Lagoas e Rússia Proletária. XXVIII SIMPÓSIO NACIONAL DE HISTÓRIA, 2015, Florianópolis, 2015. Anais... Disponível em: <http://www.snh2015. anpuh.org/resources/anais/39/1427837065_ARQUIVO_snh-2015_felipe-lacerda. pdf $>$. Acesso em: 26 jun. 2017.

LOBO, Aristides. A situação brasileira e o trabalho para o seu esclarecimento. In: ABRAMO, Fulvio; KAREPOVS, Dainis (Org.). Na contracorrente da história: documentos do trotskismo brasileiro (1930-1940). São Paulo: Sundermann, p. 75-82, 2015. (Original publicado em 1930)

LÖWY, Michael. El marxismo en América Latina. Santiago: LOME diciones, 2007.

MATTOS, Marcelo Badaró. Trabalhadores e sindicatos no Brasil. São Paulo: Expressão Popular, 2009. 
MAZZEO, Antônio Carlos. Sinfonia inacabada: a política dos comunistas no Brasil. São Paulo: Boitempo, 1999.

MAZZEO, Antônio Carlos. O Partido Comunista na raiz da via colonial do desenvolvimento do capitalismo. In: MAZZEO, Antonio Carlos; LAGOA, Maria Izabel (Org.). Corações vermelhos: os comunistas brasileiros no século XX. São Paulo: Cortez, 2003.

MORAES, João Quartim. Um livro fundador. In: BRANDÃO, O. Agrarismo e industrialismo: ensaio marxista leninista sobre a revolta de São Paulo e a guerra de classes no Brasil - 1924. 2a edição. São Paulo: Anita Garibaldi, p. 11-18, 2006.

MORAES, João Quartim.A influência do leninismo de Stalin no comunismo brasileiro. In: MORAES, João Quartim; REIS, Daniel Arão (Org.). História do marxismo no Brasil -Vol. 1. O impacto das revoluções. Campinas: Ed. Unicamp, p. 47-88, 2007.

MORAES, João Quartim.Octávio Brandão.In: PERICÁS, Luiz Bernardo; SECCO, Lincoln. (Org.). Intérpretes do Brasil: clássicos, rebeldes e renegados. São Paulo: Boitempo, p. 13-28, 2014.

NEGRO, Hélio; LEUENROTH, Edgard. O que é o maximismo ou bolchevismo. Programa comunista. São Paulo: Entremares, 2017. (Original publicado em 1919)

OITICICA, José. Princípios e fins do programa anarquista-comunista. Spartacus, Rio de Janeiro, 16 ago. 1919.

PEREIRA, Astrojildo. Formação do PCB - 1922-1926. $3^{\text {a }}$ edição. São Paulo: Anitta Garibaldi, 2012. (Original publicado em 1962)

PINHEIRO, Filipe Leite. As origens da controvérsia da revolução brasileira: um debate entre Octavio Brandão, Mario Pedrosa e Lívio Xavier. Revista da Sociedade Brasileira de Economia Política, n. 51, p. 98-120, 2018.

PINHEIRO, Filipe Leite; CURTY, Carla; MALTA, Maria de Mello. Interpretações marxistas do Brasil: o modo de produção e a revolução no Brasil. ENCUENTRO DE LA SOCIEDAD LATINOAMERICANA DE ECONOMÍA POLÍTICA Y PENSAMIENTO CRÍTICO (SEPLA), México DF, 2015.

PINHEIRO, Paulo Sérgio. Estratégias da ilusão: a revolução mundial e o Brasil 1922-1935. São Paulo: Companhia das Letras, 1991.

PRADO JR., Caio. Formação do Brasil contemporâneo - Colônia. São Paulo: Companhia das Letras, 2011. (Original publicado em 1942)

PRADO JR., Caio. Evolução política do Brasil: ensaio de interpretação materialista da história brasileira. São Paulo: Companhia das Letras, 2012. (Original publicado em 1933)

PRADO JR., Caio. A revolução brasileira. São Paulo: Companhia das Letras, 2014. (Original publicado em 1966)

RAMOS, Graciliano. São Bernardo. Rio de Janeiro: Record, 2013. (Original publicado em 1934)

REBELLO, Edgardo de Castro. Mauá e outros estudos. Rio de Janeiro: Livraria São José, 1975.

RESENDE, Leônidas de. A formação do capital e seu desenvolvimento. Brasília: Senado Federal - Conselho Editorial, 2011. (Original publicado em 1932) 
RODRIGUES, Lidiane Soares. Amar um autor: os marxistas nas universidades brasileiras e os "intérpretes do Brasil". Estudos Históricos, Rio de Janeiro, v. 32, n. 67, p. 500-529, 2019.

SCHMIDT, Afonso. Bom tempo. São Paulo: Brasiliense, 1958.

SILVA, Ângelo José. Agrarismo e industrialismo: uma primeira tentativa marxista de interpretação do Brasil. Revista de Sociologia e Política, Curitiba, n. 8, p. 43-55, 1997.

SODRÉ, Nelson Werneck. Formação histórica do Brasil. $2^{\mathrm{a}}$ edição. São Paulo: Brasiliense, 1964. (Original publicado em 1962)

ZAIDAN, Michel. PCB (1922-1929): na busca das origens de um marxismo nacional. São Paulo: Global, 1985. 